\title{
A atenção dada à saúde na agenda política do Estado da Bahia
}

\author{
The health care at the political agenda of the State of Bahia \\ La atención sanitaria en la agenda política del Estado de Bahia
}

Recebido: 22/01/2021 | Revisado: 25/01/2021 | Aceito: 26/01/2021 | Publicado: 04/02/2021

\author{
Murillo Lago Menezes \\ ORCID: https://orcid.org/0000-0002-8629-1325 \\ Universidade Estadual de Maringá, Brasil \\ E-mail: murillolago_@hotmail.com \\ Ana Maria Freire de Souza Lima \\ ORCID: https://orcid.org/0000-0002-9285-194X \\ Universidade Federal do Recôncavo da Bahia, Brasil \\ E-mail: ana.odonto@outlook.com \\ Neidiana Braga da Silva Souza \\ ORCID: https://orcid.org/0000-0002-0480-0430 \\ Universidade Estadual de Maringá, Brasil \\ E-mail: neidianabraga@gmailcom \\ Temistocles Damasceno Silva \\ ORCID: https://orcid.org/0000-0001-5932-9773 \\ Universidade Estadual de Maringá, Brasil \\ E-mail: tom@uesb.edu.br
}

\begin{abstract}
Resumo
O estudo teve como objetivo analisar a atenção dada à saúde nos planos de governo dos candidatos ao cargo de governador do Estado da Bahia, no processo eleitoral de 2018. Trata-se de uma pesquisa documental, de caráter exploratório e abordagem quanti-qualitativa. Os dados foram coletados no portal DivulgaCand do Tribunal Superior Eleitoral. Para organização e tratamento dos dados utilizou-se a análise de conteúdo de Bardin (2011). Os dados foram organizados com base nas seguintes categorias: projetos específicos; infraestrutura; qualificação da atenção básica; tecnologia da saúde; vigilância à saúde; regionalização da assistência e atenção integral à saúde. Ao observar o quantitativo de propostas por representação partidária, o Partido dos Trabalhadores (PT) e o Democratas (DEM) apresentaram maior abrangência de assuntos e volume de propostas. Ao mesmo tempo, observou-se maior incidência de pautas correlatas a infraestrutura e ações de integralidade na saúde. Contudo, as propostas diagnosticadas encontram-se difusas e dissonantes das prerrogativas elencadas nas diretrizes nacionais de saúde.
\end{abstract}

Palavras-chave: Agenda política; Saúde; Bahia.

\begin{abstract}
The study aimed to analyze the attention given to health in the government plans of candidates for the position of governor of the State of Bahia, in the 2018 electoral process. This is a documentary research, with an exploratory character and quantitative and qualitative approach. Data were collected on the DivulgaCand portal of the Superior Electoral Court. For data organization and treatment, Bardin's content analysis (2011) was used. The data were organized based on the following categories: specific projects; infrastructure; qualification of primary care; health technology; health surveillance; regionalization of assistance and comprehensive health care. When observing the number of proposals by party representation, the Partido dos Trabalhadores (PT) and Democrats (DEM) presented a greater range of subjects and volume of proposals. At the same time, there was a higher incidence of guidelines related to infrastructure and comprehensive health actions. However, the diagnosed proposals are diffuse and dissonant from the prerogatives listed in the national health guidelines.
\end{abstract}

Keywords: Political agenda; Health; Bahia.

\section{Resumen}

El estudio tuvo como objetivo analizar la atención que se le da a la salud en los planes de gobierno de los candidatos al cargo de gobernador del Estado de Bahía, en el proceso electoral de 2018. Se trata de una investigación documental, con carácter exploratorio y abordaje cuantitativo y cualitativo. Los datos fueron recolectados en el portal DivulgaCand del Tribunal Superior Electoral. Para la organización y el tratamiento de los datos se utilizó el análisis de contenido de Bardin (2011). Los datos se organizaron en base a las siguientes categorías: proyectos específicos; infraestructura; calificación de la atención primaria; tecnología de la salud; vigilancia de la salud; regionalización asistencial y asistencial integral. Al observar el número de propuestas por representación partidaria, el Partido dos 
Trabalhadores (PT) y Demócratas (DEM) presentaron una mayor variedad de temas y volumen de propuestas. Al mismo tiempo, hubo una mayor incidencia de lineamientos relacionados con infraestructura y acciones integrales de salud. Sin embargo, las propuestas diagnosticadas son difusas y disonantes de las prerrogativas enumeradas en las guías nacionales de salud.

Palabras clave: Agenda política; Salud; Bahía.

\section{Introdução}

No Brasil, a Constituição Federal de 1988 estabeleceu o princípio da descentralização dos serviços de saúde para os entes federativos - União, Estados e Municípios. Nesta lógica, as ações encontram-se interligadas por meio do estabelecimento de corresponsabilidades com vistas ao atendimento das demandas de ordem sanitária.

Do ponto de vista legislativo, a Constituição Federal (CF) de 1988 assegura o direito à saúde a todas as pessoas e preconiza as atividades e os serviços públicos de saúde enquanto elementos constituintes de uma rede regional e hierárquica vinculada ao sistema unificado e estruturado, conforme os princípios da descentralização em cada esfera de governo (Brasil, 1988).

O Sistema Único de Saúde (SUS) foi criado no Brasil através da Lei Orgânica de Saúde, n 8.080/90, no intuito de atender as demandas de saúde dos cidadãos. O SUS tornou-se reconhecido como um dos principais e mais completos sistemas de saúde do mundo, ao levar em consideração a oferta de serviços que relacionados a Atenção Primária até atendimentos complexos (Brasil, 2020).

A gestão do SUS é realizada pelos três entes federativos em que cada ente possui competências específicas. A União encontra-se responsável pela gestão e organização dos serviços de saúde. Em relação aos Estados, os mesmos devem possibilitar a descentralização das ações e atividades de saúde para os municípios. Aos municípios, compete a implementação direta dos serviços de saúde (Brasil, 1990). Diante do exposto, percebe-se a possibilidade de influência do campo político na atenção dada a saúde.

Para Abrúcio (1998, p. 170), a política nacional geralmente é guiada pela dinâmica da política estadual, levando-se em consideração a fidelidade as bases eleitorais locais enquanto fatores determinantes para as pautas das agendas partidárias. Conforme Figueiredo \& Limongi (2000), o direcionamento do apoio parlamentar as diretrizes estabelecidas pelos partidos seria um fator determinante para o processo de votação dos legisladores. No entanto, Zucco (2009) aponta que as dinâmicas do parlamento encontram-se vinculadas aos comportamentos estratégicos alicerçados em incentivos políticos oriundos do poder executivo.

Do ponto de vista da produção do conhecimento sobre política pública de saúde no Brasil, existem estudos que investigam a formulação e implementação de políticas de saúde em determinados governos, de modo específico, especialmente no contexto federal. Essas análises se referem à legitimação da promoção da saúde, a partir das ações implementadas pelo Ministério da Saúde, ao planejamento da política nacional de saúde no governo do então presidente Luiz Inácio Lula da Silva (Malta et al, 2009; Machado; Baptista \& Lima, 2010), e análise da política de saúde nos governos de Michel Temer e Jair Bolsonaro (Bravo \& Pelaez, 2020).

Bahia \& Scheffer (2016) analisaram a política de saúde nas propostas de governo em escala federal nas eleições 2014. Na mesma perspectiva, Jacobina (2017) analisou as coligações majoritárias dos candidatos e presidência da República nas eleições 2014 e suas relações com a Reforma Sanitária Brasileira. Por outro lado, Silva, Souza e Starepravo (2020) analisaram as academias da saúde nos planos de governo dos candidatos eleitos ao cargo de governador nos estados Brasileiros nas eleições 2018. 
Ao levar em consideração a produção científica supracitada, constata-se uma lacuna acerca dos estudos que permeiam a atenção dada a saúde na agenda política durante o processo eleitoral. Neste ínterim, investigar a referida temática possibilita um olhar diferenciado acerca da dinamicidade que permeia o jogo de interesses durante o processo de formação da agenda.

Partindo desse pressuposto, percebe-se que a análise das propostas governamentais apresentadas no período da campanha eleitoral é um espaço a ser explorado na esfera da política de saúde, ao considerar o processo de restabelecimento das eleições democráticas no Brasil e os impactos da criação do SUS. Nesse sentido, o presente trabalho teve enquanto questão norteadora: Qual a atenção dada à política de saúde nos planos de governo dos candidatos ao cargo de governador do estado da Bahia nas eleições de 2018? Logo, o objetivo foi analisar a atenção dada à política de saúde nos planos de governo dos candidatos a governador do Estado da Bahia nas eleições 2018.

\section{Metodologia}

Trata-se de uma pesquisa de natureza exploratória e abordagem quanti-qualitativa (Gil, 2008). A técnica utilizada para análise de dados foi a análise documental, que se caracteriza como uma coleta de dados em fontes primárias que ainda não receberam um tratamento analítico (Lakatos \& Marconi, 2001). Para tal, os dados foram coletados no portal do Tribunal Superior Eleitoral (TSE).

Nesta lógica, foi possível identificar sete candidatos ao cargo de governador, vinculados as seguintes representações político-partidárias: Partido dos Trabalhadores (PT), Partido Democratas (DEM), Partido Socialismo (PSOL), Partido do Movimento Democrático Brasileiro (MDB), Partido Renovador Trabalhista Brasileiro (PRTB), Partido da Causa Operária (PCO) e Partido Rede Sustentabilidade (REDE). Salienta-se que apenas o candidato do PCO não anexou o plano de governo na plataforma, sendo assim, o referido partido foi excluído da análise.

Quanto ao procedimento da coleta de dados utilizou-se o descritor "saúde", no intuito de identificar todos os termos existentes no documento relacionados ao objeto de estudo. Para a análise e organização dos dados, foi utilizada a análise de conteúdo (Bardin, 2011). A partir da investigação dos documentos foram pré-estabelecidas as seguintes categorias: Projetos Específicos; Infraestrutura; Qualificação da Atenção Básica; Tecnologia da Saúde; Vigilância à Saúde; Regionalização da Assistência em Saúde; e Atenção Integral à Saúde.

No primeiro momento, quantificou-se as propostas com base nas representações político-partidárias no sentido de analisar a atenção dada ao tema de forma comparativa. No segundo momento, examinou-se as propostas identificadas por meio das categorias elencadas na pesquisa com vistas a compreensão do direcionamento e amplitude da atenção à saúde.

\section{Resultados e Discussão}

Ao observar a atenção dada a política de saúde nos planos de governo dos candidatos a governador da Bahia nas eleições 2018, identificou-se um quantitativo de 163 propostas voltadas para o setor. Os dados foram organizados por representação político-partidária, conforme observado no Gráfico 1. 
Gráfico 1 - Quantitativo de Propostas para a Saúde por Representação Político-partidária.

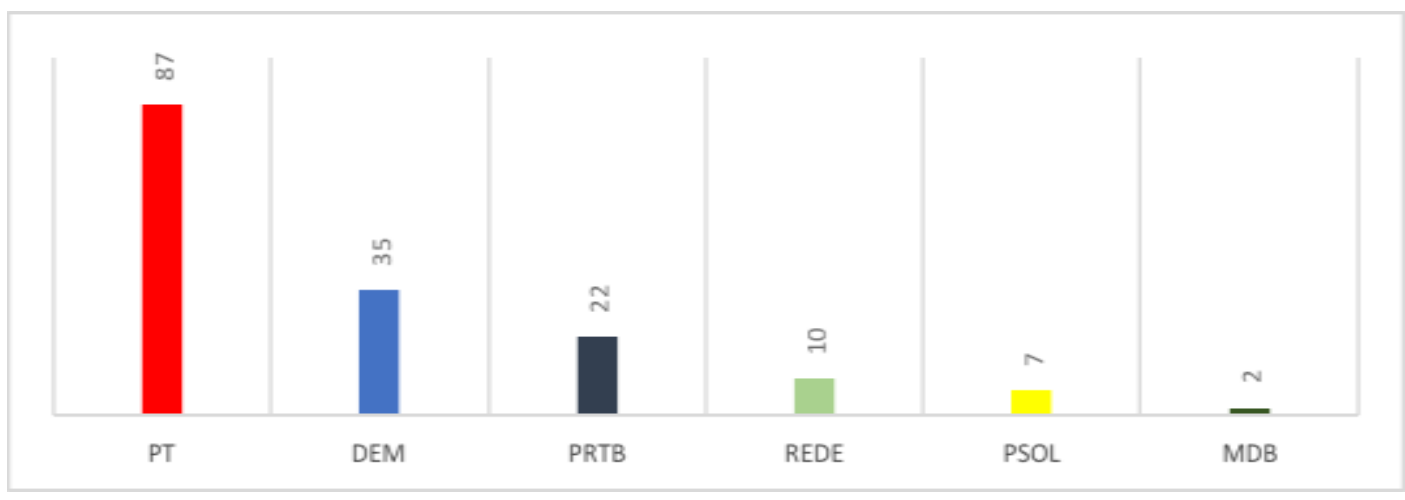

Fonte: Autores.

Dentre os seis partidos, pode-se observar que o PT apresentou o maior número de propostas para o setor, oitenta e sete (53,3\%) no total, seguido do DEM com trinta e cinco $(21,4 \%)$ e o PRTB com vinte e duas $(13,4 \%)$. Os partidos que apresentaram o menor número de proposições para a saúde foram REDE com dez (6,1\%), PSOL com sete (4,2\%) e MDB com duas $(1,2 \%)$. Logo, a atenção dada à saúde por parte do PT foi maior do que os demais partidos.

De acordo com o sociólogo brasileiro, Tarouco (2008, p. 149), “[...] as diferenças ideológicas entre partidos continuam sendo utilizadas como variável independente para explicar desde a coerência das coligações partidárias até políticas públicas implementadas pelos governos". Para o autor, o desenvolvimento de estudos na área permite a análise de determinantes políticos dos resultados em políticas públicas, a elaboração de tipologias de sistemas partidários e o desenvolvimento de estudos sobre a competição eleitoral e coalizões de governo.

No contexto latino-americano, Huber, Mustillo e Stephens (2004), identificaram uma relação positiva entre o gasto público com saúde e educação para jovens a partir da abertura comercial estabelecida por governos de esquerda. Em adição, os autores constataram uma relação positiva entre o gasto público com seguridade e bem-estar social voltado a população idosa no que diz respeito aos governos de espectro ideológico de direita e na ausência de déficit fiscal.

Em relação às categorias analíticas elencadas no estudo, considerando todos os partidos, as mais presentes foram a Infraestrutura (65) e Atenção integral (26) - Tabela 1. Esse achado é coerente com o que Soares Neto, Machado e Alves (2016) apontam como necessidade regional, considerando que a realidade das Unidades Básicas de Saúde (UBS) localizadas nas regiões Norte e Nordeste possuem infraestruturas precárias em relação as demais regiões do país. Os dados das propostas por categoria podem ser evidenciados na Tabela 1 .

Tabela 1. Propostas para a Saúde por Categoria Analítica.

\begin{tabular}{cccccccc}
\hline Partidos & $\begin{array}{c}\text { Projetos } \\
\text { Específicos }\end{array}$ & $\begin{array}{c}\text { Infra } \\
\text { Estrutura }\end{array}$ & $\begin{array}{c}\text { Atenção } \\
\text { Básica }\end{array}$ & Tecnologia & Vigilância & $\begin{array}{c}\text { Regionalização } \\
\text { daúde }\end{array}$ & $\begin{array}{c}\text { Atenção } \\
\text { Integral }\end{array}$ \\
\hline PT & $1(1,1 \%)$ & $48(55,1 \%)$ & $4(4,6 \%)$ & $8(9,2 \%)$ & $5(5,7 \%)$ & $18(20,6 \%)$ & $3(3,4 \%)$ \\
DEM & $1(2,8 \%)$ & $10(28,5 \%)$ & $5(14.3 \%)$ & $2(5,7 \%)$ & $4(11,4 \%)$ & $2(5,7 \%)$ & $11(31,4 \%$ \\
PRTB & $1(4,5 \%)$ & $4(18,2 \%)$ & $3(13,8 \%)$ & $2(9,1 \%)$ & $1(4,5 \%)$ & 0 & $11(50 \%)$ \\
REDE & $7(70 \%)$ & $2(20 \%)$ & 0 & $1(10 \%)$ & 0 & 0 & 0 \\
PSOL & 0 & 0 & $3(42,8 \%)$ & 0 & 0 & 0 & 0 \\
MDB & 0 & $1(50 \%)$ & $1(50 \%)$ & 0 & 0 & 0
\end{tabular}

Fonte: Autores, com base em Tribunal Superior Eleitoral (2018).

É possível observar o número e a porcentagem de propostas por categoria analítica. As categorias Regionalização da Assistência em Saúde e Atenção Básica obtiveram um quantitativo relevante, vinte e três (23) e dezesseis (16), 
respectivamente. Para Fernandes (2017), é lógico considerar que diversas maneiras de execução da Regionalização da Saúde com níveis variados de resultado vêm ocorrendo, com grau moderado de simultaneidade e correspondência com a descentralização dos com moderada relação e sincronia com os princípios de descentralização dos serviços e o conceito de rede. Assim, as propostas para saúde devem estar coerentes com as diretrizes de regionalização e trabalho em rede, no intuito de potencializar a implementação dos serviços.

A categoria Tecnologia obteve treze (13) propostas, por outro lado, Projetos Específicos e Vigilância, obtiveram o menor número de proposições, dez (10) cada uma. Lorenzetti et al (2012) afirmam que, os temas relacionados à tecnologia e inovação tecnológica estão em pauta nos meios de comunicação da sociedade e nas agendas governamentais, nas empresas, instituições que atuam com pesquisas e várias organizações sociais, com grande influência área da saúde. Logo, é necessário utilizar os instrumentos tecnológicos para agilizar os atendimentos nas instituições de saúde, bem como auxiliar na elaboração do planejamento e execução das políticas.

Os partidos PT, REDE e PSOL delinearam o total de 107 propostas, enquanto o DEM, PRTB e MDB, 50\% a menos, com apenas 59 proposições para a política em questão. Das propostas apresentadas pelo PT 55,1\% (48) foram relacionadas à Infraestrutura, 20,6\% (18) a Regionalização em Saúde e 9,2\% (8) para a Tecnologia da Saúde. Enquanto, das propostas do DEM, 31, 4\% (11) eram para a Atenção Integral à saúde, 28,5\% (10) eram de Infraestrutura, e 14,3\% (5) para a Atenção Básica.

Desse modo, o PT entende que, no contexto baiano, os problemas relacionados à infraestrutura e regionalização da saúde devem ser priorizados; enquanto o DEM estabeleceu como preferência a Atenção Integral em saúde. A Política Estadual de Atenção Básica apresenta a integralidade como diretriz para o desenvolvimento dos programas, projetos e ações voltados para a política. Assim, torna-se necessário analisar a viabilidade das soluções apresentadas pelos partidos para os problemas das referidas áreas.

No que se refere às propostas divulgadas pelo PRTB, 50\% (11) foram para a Atenção Integral à Saúde; 18,2\% (4) eram da Infraestrutura; e 13,8\% (3) para a Atenção Básica. Da mesma forma, o PSOL apresentou 42,8\% (3) para a Atenção Básica; 42,8\% (3) foram para Regionalização da Assistência em Saúde; e 14,3\% (1) para a Atenção Integral à Saúde. O PRTB e o PSOL reconhecem a necessidade de ações para os serviços básicos e integrais no contexto baiano. No que se refere as propostas do MDB 50\% (1) foram para a Infraestrutura e outros 50\% (1) para a Atenção Básica. Assim como o REDE destinou 70\% (7) para os Projetos Específicos; 20\% (2) era da Infraestrutura; e 10\% (1) para a Tecnologia da Saúde.

Em termos gerais, ao observar as categorias analíticas elencadas e o quantitativo de proposições destinadas a cada uma, precisa-se reconhecer a necessidade de uma diagnose mais precisa acerca da realidade do Estado baiano, para que a formação da agenda governamental seja condizente aos problemas existentes no referido contexto. Nunes (2011) revela que os gestores da saúde precisam reconhecer a necessidade de enfrentamento dos problemas referentes à gestão do Programa Saúde da Família (PSF), bem como as insuficiências das ações de integralidade em municípios baianos.

Além de apresentar os dados quantitativos referentes as propostas ofertadas pelos partidos políticos analisados, tornase necessário compreender a natureza das proposições, bem como os significados, no intuito de perceber como cada legenda partidária idealiza as políticas de saúde. Nesse sentido, a síntese descritiva das propostas pode ser visualizada no Quadro 1. 
Research, Society and Development, v. 10, n. 2, e6410212283, 2021

(CC BY 4.0) | ISSN 2525-3409 | DOI: http://dx.doi.org/10.33448/rsd-v10i2.12283

Quadro 1 - Síntese das Propostas para a Saúde por Representação Político-partidária.

\begin{tabular}{|c|c|c|c|c|c|c|c|}
\hline Sigla & $\begin{array}{c}\text { Prog. e Proj. } \\
\text { Específicos }\end{array}$ & Infraestrutura & Aten. Básica & Tecnologia & Vigilância & Regionalização & Aten. Integral \\
\hline PT & $\begin{array}{l}\text { Criação do } \\
\text { "Projeto Acolher" } \\
\text { - assistência à } \\
\text { saúde mental na } \\
\text { rede escolar. }\end{array}$ & $\begin{array}{l}\text { Construção, } \\
\text { revitalização e } \\
\text { reforma de } \\
\text { espaços para a } \\
\text { saúde }\end{array}$ & $\begin{array}{c}\text { Ampliação de } \\
\text { unidades básicas; } \\
\text { oferta de } \\
\text { equipamentos às } \\
\text { equipes de saúde; } \\
\text { implantação de } \\
\text { prontuário } \\
\text { eletrônico. }\end{array}$ & $\begin{array}{l}\text { Conexão digital; } \\
\text { prontuário } \\
\text { eletrônico; } \\
\text { tecnologia de } \\
\text { informação para a } \\
\text { vigilância } \\
\text { sanitária. }\end{array}$ & $\begin{array}{c}\text { Melhorias } \\
\text { gerais nos } \\
\text { centros de saúde } \\
\text { voltados para a } \\
\text { vigilância em } \\
\text { saúde. }\end{array}$ & $\begin{array}{l}\text { Construção e } \\
\text { implantação de } \\
\text { centros, hospitais } \\
\text { e unidades de } \\
\text { saúde de alta } \\
\text { complexidade, } \\
\text { para atender } \\
\text { diversas regiões. }\end{array}$ & $\begin{array}{l}\text { Ampliação de } \\
\text { mutirões de } \\
\text { cirurgias; } \\
\text { organização de } \\
\text { solicitação dos } \\
\text { serviços; } \\
\text { implantação de } \\
\text { centros e centrais } \\
\text { de atendimento. }\end{array}$ \\
\hline DEM & $\begin{array}{l}\text { Criação de um } \\
\text { programa de } \\
\text { atenção integral à } \\
\text { saúde }\end{array}$ & $\begin{array}{l}\text { Construção, } \\
\text { revitalização e } \\
\text { ampliação de } \\
\text { hospitais e redes } \\
\text { estaduais de } \\
\text { saúde. }\end{array}$ & $\begin{array}{l}\text { Qualificação do } \\
\text { acesso à saúde; } \\
\text { ampliação da } \\
\text { cobertura de saúde } \\
\text { bucal; e solução } \\
\text { dos problemas da } \\
\text { atenção básica. }\end{array}$ & $\begin{array}{l}\text { Criação de novos } \\
\text { meios de } \\
\text { comunicação } \\
\text { entre os } \\
\text { municípios; e } \\
\text { retroalimentação } \\
\text { do sistema de } \\
\text { encaminhamentos } \\
\text { dos serviços de } \\
\text { saúde. }\end{array}$ & $\begin{array}{c}\text { Promoção de } \\
\text { ações } \\
\text { preventivas e } \\
\text { educativas para } \\
\text { doenças } \\
\text { infectocontagios } \\
\text { as; execução da } \\
\text { vigilância em } \\
\text { saúde; oferta de } \\
\text { apoio técnico e } \\
\text { financeiro para } \\
\text { as ações. }\end{array}$ & $\begin{array}{l}\text { Descentralização } \\
\text { dos serviços; } \\
\text { desenvolvimento } \\
\text { do processo de } \\
\text { regionalização da } \\
\text { assistência em } \\
\text { saúde; } \\
\text { implantação de } \\
\text { um escritório } \\
\text { regional de saúde. }\end{array}$ & $\begin{array}{c}\text { Aumento da } \\
\text { cobertura da saúde } \\
\text { bucal; } \\
\text { fornecimento de } \\
\text { materiais da } \\
\text { saúde; promoção } \\
\text { de medidas } \\
\text { sanitárias; oferta } \\
\text { de exames } \\
\text { médicos; } \\
\text { atendimento ágil } \\
\text { de urgência e } \\
\text { emergência }\end{array}$ \\
\hline PSOL & - & - & $\begin{array}{c}\text { Apoio técnico à } \\
\text { atenção primária; } \\
\text { e construção; } \\
\text { criação de redes } \\
\text { de apoio; e } \\
\text { incentivo a várias } \\
\text { políticas de saúde. }\end{array}$ & - & - & $\begin{array}{l}\text { Articulação das } \\
\text { ações por meio } \\
\text { das comissões } \\
\text { intergestoras; } \\
\text { desenvolvimento } \\
\text { intersetorial das } \\
\text { ações; gestão } \\
\text { descentralizada. }\end{array}$ & $\begin{array}{l}\text { Aperfeiçoamento } \\
\text { das redes de } \\
\text { atenção à saúde. }\end{array}$ \\
\hline MDB & - & $\begin{array}{c}\text { Revitalização } \\
\text { das estruturas } \\
\text { de saúde do } \\
\text { Estado. }\end{array}$ & $\begin{array}{l}\text { Reorganização } \\
\text { das ações em } \\
\text { saúde por meio da } \\
\text { rede pública e } \\
\text { privada de } \\
\text { emergência. }\end{array}$ & - & - & - & ( \\
\hline PRTB & $\begin{array}{c}\text { Ampliação do } \\
\text { Programa "Saúde } \\
\text { em Movimento" - } \\
\text { oferecer } \\
\text { atendimento } \\
\text { oftalmológico, ao } \\
\text { câncer de mama e } \\
\text { internações } \\
\text { domiciliares. }\end{array}$ & $\begin{array}{l}\text { Construção e } \\
\text { implantação de } \\
\text { unidades e } \\
\text { centros de } \\
\text { saúde. }\end{array}$ & 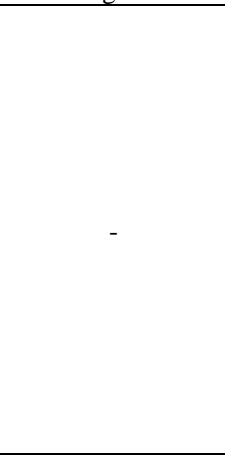 & $\begin{array}{c}\text { Suporte e } \\
\text { ampliação da } \\
\text { "Telemedicina"; } \\
\text { criação de um } \\
\text { aplicativo para } \\
\text { facilitar a } \\
\text { comunicação com } \\
\text { médicos. }\end{array}$ & $\begin{array}{l}\text { Ampliação da } \\
\text { Rede de } \\
\text { Laboratórios de } \\
\text { Saúde Pública - } \\
\text { RELSP. }\end{array}$ & - & $\begin{array}{c}\text { Oferta } \\
\text { especializada dos } \\
\text { serviços; garantir } \\
\text { atenção integral à } \\
\text { saúde para } \\
\text { populações; } \\
\text { prevenção e } \\
\text { tratamento das } \\
\text { doenças crônicas; } \\
\text { prevenção e } \\
\text { controle das } \\
\text { doenças } \\
\text { sexualmente } \\
\text { transmissíveis. } \\
\end{array}$ \\
\hline REDE & $\begin{array}{c}\text { Programas: } \\
\text { Check-up Bahia; } \\
\text { Saúde Básica; } \\
\text { Saúde Integral; } \\
\text { Médico } \\
\text { Especialista; } \\
\text { Corpo e Mente } \\
\text { Limpa - } \\
\text { tratamento de } \\
\text { dependentes } \\
\text { químicos; } \\
\text { Hospital } \\
\text { Sustentável - } \\
\text { aperfeiçoamento } \\
\text { da gestão; Saúde } \\
\text { Melhor. }\end{array}$ & $\begin{array}{l}\text { Modernização } \\
\text { da rede } \\
\text { hospitalar; } \\
\text { Criação de } \\
\text { Centros de } \\
\text { referência da } \\
\text { Saúde }\end{array}$ & - & $\begin{array}{l}\text { Incentivo para a } \\
\text { realização de } \\
\text { pesquisas sobre a } \\
\text { saúde }\end{array}$ & - & - & - \\
\hline
\end{tabular}

Fonte: Autores, com base em Tribunal Superior Eleitoral (2018). 
No Quadro 1 podem ser enviadas as propostas estabelecidas por representação partidária e categoria analítica. O partido MDB apresentou duas propostas, sendo uma de Infraestrutura - revitalização dos espaços, e uma para a Atenção Básica - organização e controle das ações através das redes pública e privada. O partido DEM divulgou a proposição de realizar uma reorganização administrativa na Secretaria de Saúde da Bahia (SESAB).

Já o PRTB apresentou estratégias para a cooperação entre os entes federados, por meio da regionalização; para a Infraestrutura, construção e reforma de unidades e centros de saúde; e para a Atenção Integral à Saúde - serviços especializados, aumento dos leitos nas Unidades de Terapia Intensiva - UTIs, tratamento das doenças crônicas, e serviços especializados de média e alta complexidade. Pinheiro e Luz (2003, p. 13) argumentam que, é necessário apropriar-se da integralidade como um eixo orientador das ações em saúde e propor "[...] uma nova forma de gestão de cuidados nas instituições de saúde, permitindo o surgimento de experiências inovadoras na incorporação e desenvolvimento de novas tecnologias assistenciais".

O PSOL indicou o planejamento das ações relacionado ao meio ambiente; propôs para a Atenção Básica - apoio técnico, redes de ações em saúde e incentivo às diversas políticas; para a Regionalização - articulação das ações por meio de comissões, intersetorialidade e descentralização das atividades. Conforme Lima e Xavier (2009), tais ações em rede estabelecem espaços de educação permanente, com múltiplos saberes e criam relações sólidas, comprometidas com os fundamentos do SUS.

Outro ponto a ser observado é que o partido REDE, propôs a criação de Projetos Específicos para a oferta de exames; ações integrativas; tratamento de dependentes químicos; descentralização da rede hospitalar; aprimoramento da gestão; qualificação da rede básica e dos serviços de prevenção; para a Infraestrutura - modernização da rede hospitalar e criação de centros de referência em saúde. Segundo o portal eletrônico oficial da SESAB, o Estado dispõe de nove Centros de Referência que atendem às diversas áreas, a saber: autismo; diabetes e endocrinologia; informações antiveneno; saúde do idoso; pessoa com deficiência; doenças endêmicas; oncologia; doenças sexualmente transmissíveis; e saúde do trabalhador. Vale ressaltar que, a maioria dessas instituições estão localizadas na capital do Estado, Salvador.

Tendo em vista todos os partidos, houve menor ocorrência de propostas para as categorias de Tecnologia da Saúde, Projetos Específicos e Vigilância em Saúde, e maior incidência de propostas para a Infraestrutura e Atenção Integral em saúde, com destaque para os dois partidos que apresentaram o maior número de propostas - PT e DEM. O PT, propôs para a Infraestrutura - construção e qualificação de hospitais, policlínicas e unidades de saúde; para a Regionalização em Saúde criação de unidades de alta complexidade em algumas regiões, inserção de serviços radioterápicos em hospitais e melhorias nas Unidades de Pronto Atendimento-UPAs. Os dados estão em consonância com a diretriz IX da Política Estadual de Atenção Básica, a qual propõe a regionalização como estratégia para garantir a equidade nos serviços de saúde.

Por outro lado, o DEM apresentou para a Infraestrutura - construção e revitalização de hospitais e redes de atenção à saúde; para a Atenção Integral - serviços ambientais, sanitários e de saúde bucal; cuidados aos pré-diabéticos; oferta de atividades físicas e diversos materiais de saúde. Esses dados se aproximam das ações de cuidado integral à saúde realizadas por equipes multiprofissionais nos Núcleos de Apoio à Saúde da Família - NASF (Almeida, 2016).

Copque e Trad (2005) destacaram que, o período que antecede as eleições municipais é marcado por instabilidades para os projetos, representando incertezas quanto a continuidade das ações, e, nas eleições estaduais esse cenário não é diferente, conforme pôde ser observado nos dados ora apresentados. Diante do exposto, torna-se possível visualizar a ambiguidade que permeia a agenda política correlata as questões de saúde no estado da Bahia. 


\section{Considerações Finais}

Em virtude dos fatos mencionados, percebe-se que os planos de governo se apresentam como um conjunto de ideias sobre o planejamento e organização das ações com potencial para serem inseridas na agenda governamental. Neste contexto, a política de saúde nas eleições 2018 para o cargo de governador no estado da Bahia obteve o quantitativo de 163 propostas. Salienta-se que o PT e o DEM apresentaram maior abrangência de ações e volume de propostas, no que se refere à todas as categorias estabelecidas na pesquisa.

Outro ponto a ser considerado é que entre as categorias elencadas, a Infraestrutura e a Atenção Integral em saúde foram áreas prioritárias no bojo das propostas de governo investigadas, com destaque para o PT e o DEM, os quais obtiveram o maior número para as categorias citadas. Por outro lado, na categoria Programas e Projetos Específicos, apenas o partido REDE divulgou um número expressivo de propostas, destacando e afirmando a defesa dos direitos das minorias sociais. Houve um número reduzido de ofertas também para a tecnologia da saúde, a exceção do PT, que apresentou oito propostas. Apesar do MDB indicar a saúde como prioridade no seu plano de governo, apresentou apenas 2 propostas.

Alguns programas de governo indicaram aproximação com a Política Estadual de Atenção Básica, no entanto, não foi possível confirmar se os partidos de fato utilizaram a referida política para a elaboração das suas propostas. Além disso, os partidos REDE e PSOL apresentaram objetivos alinhados a algumas diretrizes da Política Nacional de Promoção da Saúde, como por exemplo, ênfase na prevenção de doenças e preservação do meio ambiente.

Por fim, percebe-se que apesar das diferenças quantitativas identificadas entre os partidos, os conteúdos abordados nas pautas estão muito próximos. Logo, a classificação político-partidária não se apresenta como uma variável capaz de explicar a atenção dada à política de saúde no Estado da Bahia.

Vale ressaltar que nem todas as propostas são consideradas pelos representantes governamentais após assumirem o poder executivo, por isso a necessidade da realização de novas investigações que relacionem os planos de governo com a formação da agenda governamental e a formulação das políticas de saúde no Estado da Bahia. Para tal, deve-se levar em consideração o ciclo político enquanto prerrogativa da análise científica no sentido de ampliar o conhecimento sobre a dinâmica em questão.

\section{Referências}

Almeida, E. R (2016). A Gênese dos Núcleos de Apoio à Saúde da Família. Tese (Doutorado em Saúde Coletiva) - Instituto de Saúde Coletiva, Universidade Federal da Bahia. Salvador/BA.

Bahia (2013). Política Estadual de Atenção Básica. Salvador: Secretaria da Saúde do Estado da Bahia.

Bahia (2021). Centros de Referência. Saúde/BA.

Bahia, L., \& Scheffer, M (2016). A Saúde nos programas de governo dos candidatos a Presidente da República do Brasil nas eleições de 2014: notas preliminares para o debate. Revista Discente do Programa de Pós-Graduação em História - UFJF, 2(3).

Bardin, L (2011). Análise de Conteúdo. São Paulo.

Brasil (1990). Lei $n^{\circ} 8.080$, de 19 de setembro de 1990. Dispõe sobre as condições para a promoção, proteção e recuperação da saúde, a organização e o funcionamento dos serviços correspondentes e dá outras providências. Brasília/DF.

Brasil (2006). Política Nacional de Promoção da Saúde. Brasília: Ministério da Saúde, (3a ed.).

Brasil (2020). Ministério da Saúde. O que é o Sistema Único de Saúde (SUS)?

Brasil (1988). Constituição da República Federativa do Brasil: promulgada em 5 de outubro de 1988. (4a ed.), Saraiva.

Bravo, M. I. S., \& Pelaez, E. J (2020). A Saúde nos governos Temer e Bolsonaro: Lutas e resistências. Estado, Democracia e Saúde, 153 , 170.

Copque, H. L. F., \& Trad L. A. B (2005). Programa Saúde da Família: a experiência de implantação em dois Municípios da Bahia. Revista de Epidemiologia e Serviços de Saúde, 14(4), 223-233.

Fernandes, F. M. B (2017). Regionalização no SUS: uma revisão crítica. Ciência \& Saúde Coletiva, (22)4, 1311-1320. 
Research, Society and Development, v. 10, n. 2, e6410212283, 2021

(CC BY 4.0) | ISSN 2525-3409 | DOI: http://dx.doi.org/10.33448/rsd-v10i2.12283

Figueiredo, A. C., \& Limongi, F (2000). “Presidential power, legislative organization, and party behavior in Brazil.” Comparative Politics, 32, $151-170$.

Gil, A.C (2008). Como elaborar projetos de pesquisa. Atlas, v. 5.

Huber, E., Mustillo, T., \& Stephens, J (2004). Determinantes do gasto social na América Latina e no Caribe in: Congress International of Latin American Studies Association. Washington.

Jacobina, A. T (2017). Análise dos programas das coligações majoritárias apresentados às eleições de 2014 e a Reforma Sanitária Brasileira. Saúde em Debate [online], v. 41, spe 3 .

Lima, J. O, \& Xavier, S. S (2009). Gestão de redes e educação permanente em saúde: características, limites e perspectivas. Rev. baiana saúde pública, 33(1):121-30.

Lorenzetti, J., Trindade, L. L., Pires, D. E. P., \& Ramos, F. R. S (2012). Tecnologia, Inovação Tecnológica e Saúde: uma reflexão necessária. Texto Contexto Enferm, Abr-Jun, 21(2):432-9.

Machado, C. V, Baptista, T. W. F, \& Lima, L. D (2010). O planejamento nacional da política de saúde no Brasil: estratégias e instrumentos nos anos 2000. Ciência \& Saúde Coletiva, 2010,15(5):2367-82.

Malta, D. C, Castro, A. M, Gosch, C. S, Cruz, D. K. A, Bressan, A, Nogueira, J. D, et al. (2009). A Política Nacional de Promoção da Saúde e a agenda da atividade física no contexto do SUS. Epidemiologia e Serviços de Saúde, 18(1):79-86.

Nunes, C. A (2011). A Integralidade da Atenção e o Programa Saúde da Família: estudo de caso em um município do interior da Bahia. Tese (Doutorado) Instituto de Saúde Coletiva. Universidade Federal da Bahia, Bahia.

Pinheiro, R., \& Luz, M. T (2003). Práticas eficazes x modelos ideais: ação e pensamento na construção da integralidade. In: Pinheiro R, Mattos R. A, organizadores. Construção da integralidade: cotidiano, saberes e práticas em saúde. Rio de Janeiro: UERJ/IMS: ABRASCO.

Scheeffer, F (2018). A alocação dos partidos no espectro ideológico a partir da atuação parlamentar. E-legis, (27)119-142.

Silva, T. D., Souza, S. S., \& Starepravo, F. A (2020). Academia da Saúde, Academia da Cidade e Academia ao Ar Livre nas agendas política e governamental dos estados brasileiros. Rev Bras Ativ Fís Saúde, 25:e163.

Soares Neto, J. J, Machado, M. H, \& Alves, C. B (2016). O Programa Mais Médicos, a infraestrutura das Unidades Básicas de Saúde e o Índice de Desenvolvimento Humano Municipal. Ciênc Saúde Colet, 21(9):2707-2716.

Tarouco, G. S (2008). Classificação ideológica dos partidos brasileiros: notas de pesquisa. In: Encontro Anual Da ANPOCS, 32, 2008. Anais. Ilhéus: ANPOCS.

Zucco, C (2009). Ideology or what? Legislative behavior in multipartypresidentialist settings. Journal of Politics, 71(3), 1.076-1.092. 